\title{
White Light Emission of ZnO-Cu Nano-Films
}

\author{
V.S. Khomchenko ${ }^{1, *}$, O.S. Lytvyn ${ }^{1,2}$, M.A.Mazin ${ }^{1}$, V.E. Rodionov ${ }^{1}$, S.I.Vlaskina ${ }^{1}$, Demydiuk P.V. ${ }^{3}$, \\ S.U.Yuldashev ${ }^{4}$ \\ ${ }^{1}$ V.E.Lashkarev Institute of Semiconductors Physics, National Academy of Sciences of Ukraine, Ukraine \\ ${ }^{2}$ Borys Grinchenko Kyiv University, Ukraine \\ ${ }^{3}$ Institute of Materials Science Problems, National Academy of Sciences of Ukraine, Ukraine \\ ${ }^{4}$ Quantum-Functional Semiconductor Research Center, Dongguk University, South Korea
}

Copyright $(2016$ by authors, all rights reserved. Authors agree that this article remains permanently open access under the terms of the Creative Commons Attribution License 4.0 International License

\begin{abstract}
The $\mathrm{ZnO}$ films were prepared by reactive rf-magnetron sputtering on silicon and sapphire substrates. For $\mathrm{Cu}$-doping of the $\mathrm{ZnO}$ films, the close space sublimation method (CSS) was used at atmospheric pressure in air. After $\mathrm{CSS}$ processing, the $\mathrm{ZnO}$ and $\mathrm{ZnO}-\mathrm{Cu}$ films were annealed in a wet media. The reference $\mathrm{ZnO}-\mathrm{Cu}$ films, obtained from $\mathrm{ZnO}-\mathrm{Cu}$ target by electron-beam evaporation (EBE) were treated at the same conditions. The microstructure and optical properties of the samples were compared and studied by atomic force microscopy (AFM), X-ray diffraction (XRD), photoluminescence (PL) and cathodoluminescence (CL) spectra. XRD results indicated that all the $\mathrm{ZnO}$ films have a polycrystalline hexagonal structure. The surface and crystal quality of $\mathrm{ZnO}$ thin film was improved when doped with $\mathrm{Cu}$. The shape of the spectrum depends on the method of doping. Spectrum of the reference $\mathrm{ZnO}-\mathrm{Cu}$ films has green band only. Spectrum of $\mathrm{ZnO}-\mathrm{Cu}$ films consists of three emission bands at doping by CSS. The first band is in a blue region with a maximum at $465 \mathrm{~nm}$. The second and third bands are in the green and orange regions with maximum at 520 and 580-600 nm, respectively. The green band is the most intensive. As a consequence, the emission looks like white light. Origin of observed emission bands is discussed.
\end{abstract}

Keywords Thin Films, $\mathrm{ZnO}, \mathrm{Cu}$, Close Space Sublimation, XRD, AFM, Photoluminescence, Cathodoluminescence

\section{Introduction}

Zinc oxide is a promising material for a variety of practical applications as a transparent conductive electrode, heterojunction laser diode, ultraviolet (UV) laser, luminescent material, etc. [1]. $\mathrm{ZnO}$ is a wide and direct band gap semiconductor $(3.37 \mathrm{eV})$ whose room temperature photoluminescence (PL) is of the greatest importance. The $\mathrm{ZnO}$ has various luminescent transitions as different preparation techniques lead to varying structures and surface properties in $\mathrm{ZnO}$. Generally, $\mathrm{ZnO}$ exhibits two kinds of emissions: one is excitonic ultraviolet (UV) at 370-380 nm and the other is visible (VS) emission with a peak at 510-530 nm [2]. Many studies have attempted to improve the properties of $\mathrm{ZnO}$ by doping with transition metals such as aluminium [3], manganese [4], indium [5], and copper $(\mathrm{Cu})$ [6-8]. Among them, $\mathrm{Cu}$ is mostly a preferable dopant due to follow: the $\mathrm{Cu}^{2+}$ has similar with $\mathrm{Zn}^{2+}(0.074 \mathrm{~nm})$ ionic radii $0.073 \mathrm{~nm}[9]$ and relatively easy replace zinc in the lattice forming complex with neighbor oxygen ions. The $\mathrm{Cu}$ can interact with intrinsic defects of $\mathrm{ZnO}$ resulting in formation of different defect complex which effect optical transitions in $\mathrm{ZnO}$. It was found that this allows changing of the emission color from green to white [10]. $\mathrm{Cu}$-doped $\mathrm{ZnO}$ has shown an essential improvement on electrical, optical, magnetic and luminescence performance [11]. Different techniques are used to grow $\mathrm{ZnO}-\mathrm{Cu}$ films such as pulsed laser deposition [12], magnetron sputtering [13], metal-organic chemical vapor deposition under atmospheric pressure [14]. The $\mathrm{Cu}$ can be added to $\mathrm{ZnO}$ films during the growth process [7, 8 , $10,14]$ or copper impurity can be introduced into already deposited $\mathrm{ZnO}$ film $[15,16]$ by different techniques. In this paper the isothermal close space sublimation (CSS) process [17] has been used for doping $\mathrm{ZnO}$ films by $\mathrm{Cu}$ under atmospheric pressure. Deposited $\mathrm{ZnO}-\mathrm{Cu}$ films were heated in humid air. Beneficial effect of water vapor on growth of $\mathrm{ZnO}$ crystals and on structural properties of $\mathrm{ZnO}$ films is well known for a long time [18, 19, 20]. This method represents favorable condition at appropriate temperature for the impurity to be effectively introduced into $\mathrm{ZnO}$ film. The present work was aimed to investigate the effect of $\mathrm{Cu}$ doping by CSS technique on structure and luminescent properties of $\mathrm{ZnO}$ thin films.

\section{Materials and Methods}

$\mathrm{ZnO}$ films (approximately $0.5 \mu \mathrm{m}$ ) were deposited by radio frequency magnetron sputtering of $\mathrm{Zn}$ target in vacuum 
chamber on silicon and sapphire substrates. The $\mathrm{ZnO}$ films were deposited at substrate temperature $\mathrm{T}_{\mathrm{s}}=150{ }^{\circ} \mathrm{C}$. The 10 $\mathrm{nm}$ of $\mathrm{SiN}_{\mathrm{x}}$ buffer layer was introduced to accommodate lattice mismatch between $\mathrm{ZnO}$ and $\mathrm{Si}$. The mismatch of lattice constants $(15 \%)$ and thermal expansion coefficients $(56 \%)$ between $\mathrm{ZnO}$ and $\mathrm{Si}$ are quite large. $\mathrm{SiN}_{\mathrm{x}}$ has a relatively small lattice mismatch $(5 \%)$ and thermal expansion coefficient. The deposition of films was carried out by layer-by-layer method that was detailed in [13].

The $\mathrm{Cu}$ doping of $\mathrm{ZnO}$ films was performed by CSS processes at atmospheric pressure during 1 hour. Copper block was used as $\mathrm{Cu}$ source and $\mathrm{ZnO} / \mathrm{SiN}_{\mathrm{x}} / \mathrm{Si}$ and $\mathrm{ZnO} / \mathrm{a}-\mathrm{Al}_{2} \mathrm{O}_{3}$ films were used as a substrate. The $\mathrm{Cu}$ source and the substrate were separated by a ceramic spacer with thickness of $1 \mathrm{~mm}$. The $\mathrm{Cu}$ was introduced in the $\mathrm{ZnO}$ by condensation of their vapor on the film surface in the furnace at the temperature $500-600{ }^{\circ} \mathrm{C}$. The doping method is based on the process of the impurity diffusion through the surface of the film under heating. This method allows correlating the concentration of the doping elements by changing the temperature in the furnace. We have found that noticeable changes of luminescence spectra start at the temperature higher $500{ }^{\circ} \mathrm{C}$. The doping temperature varied within $500-700{ }^{\circ} \mathrm{C}$. The $\mathrm{Cu}$ vapor pressure was within $10^{-9}-10^{-4} \mathrm{~Pa}$ [21].We used three doping levels. The low level of doping corresponds to $1.33 \times 10^{-9} \mathrm{~Pa}$.The mediate level of doping corresponds to $1.33 \times 10^{-7} \mathrm{~Pa}$. The high level of doping corresponds to $7 \times 10^{-5} \mathrm{~Pa}$. After the $\mathrm{CSS}$ processing $\mathrm{ZnO}-\mathrm{Cu}$ films were annealed at the temperature $600{ }^{\circ} \mathrm{C}$ in wet media during 1 hour (a density of water vapors was about 0.08 $\mathrm{g} / \mathrm{m}^{3}$ ). Beside the $\mathrm{ZnO}-\mathrm{Cu}$ films the $\mathrm{ZnO}$ reference films were treated at the same conditions in order to separate the effects of the temperature annealing on the properties of films.

The $\mathrm{ZnO}-\mathrm{Cu}$ films were deposited by $\mathrm{EBE}$ from $\mathrm{ZnO}-\mathrm{Cu}$ target onto sapphire substrates. The $\mathrm{Cu}$ concentration in the target was from 0.06 to $0.25 \mathrm{wt} \%$. The substrate was heated to $150{ }^{\circ} \mathrm{C}$ and the film thickness was $0.6 \mu \mathrm{m} . \mathrm{ZnO}: \mathrm{Cu}$ films were annealed at the temperature $600{ }^{\circ} \mathrm{C}$ in wet media during 1 hour (a density of water vapors was about $0.08 \mathrm{~g} / \mathrm{m}^{3}$ ).

$\mathrm{X}$-ray diffraction measurements (XRD) were performed by DRON-3M X-ray diffractometer operated with $\mathrm{CuK}_{\alpha}$ irradiation $(\lambda=0.1541 \mathrm{~nm})$. The morphological properties of films studied by NanoScope IIIa Dimension 3000 atomic force microscope. To provide high lateral resolution and sensitivity the tapping mode of measurements was applied. Measurements performed using commercial NSG-11 Si probes with the nominal tip apex radius of $10 \mathrm{~nm}$ (NT-MDT, Russia). Photoluminescence (PL) emission was excited by a He-Cd laser $\left(\lambda_{\text {exc }}=325 \mathrm{~nm}\right.$, power $\left.25 \mathrm{~mW}\right)$. The PL spectra were recorded with the use of a Horiba JobinYvon T64000 spectrometer. The cathodoluminescence (CL) signal was detected using an Oxford Instruments MonoCL2 system in Philips XL30 SEM at the electron energy in the beam of $15 \mathrm{keV}$. The spectra were measured at room temperature.

\section{Results and Discussions}

XRD measurements showed that all $\mathrm{ZnO}$ films have a polycrystalline hexagonal structure. The films consist of grains with a strong preferred (002) orientation. Doping by a small amount of copper does not change the texture of the $\mathrm{ZnO}$ film. The surface morphology modification caused by doping process was investigated by AFM since an introduction of the $\mathrm{Cu}$ impurity by CSS methods is based on the diffusion of $\mathrm{Cu}$ ions into the films through the grains or grain boundaries. Figure 1 illustrates the effect of doping on morphology of film surface at the mediate level of doping. The surface of reference $\mathrm{ZnO}$ film (Fig.1,a) shows complex nano-granular structure. The smallest grains (diameters of 15-20nm) aggregated into elongated clusters (typically $360 \times$ $60 \mathrm{~nm})$. Clusters are randomly oriented and separated with depressions of the 10-15 nm in depth. Surface morphology transforms drastically at the $\mathrm{Cu}$ doping (Fig. 1b). Many elongated clusters transforms into faceted pyramidal grains. The size of their long axis ranged within $300-450 \mathrm{~nm}$. The size of a small fraction of grains increased up to the 60 $-120 \mathrm{~nm}$. Depth of the depressions between grains enlarged to the $25-50 \mathrm{~nm}$. From statistical point of view, the surface transformation at doping could be illustrated with height histograms. Height distributions for $\mathrm{ZnO}$ (curve 1) and $\mathrm{ZnO}-\mathrm{Cu}$ (curve 2) films are shown in Fig. 1c. Significant widening of the surface height takes place for doped films. Corresponding RMS values are equal to the 9 and $17 \mathrm{~nm}$ for initial and $\mathrm{Cu}$-doped films.

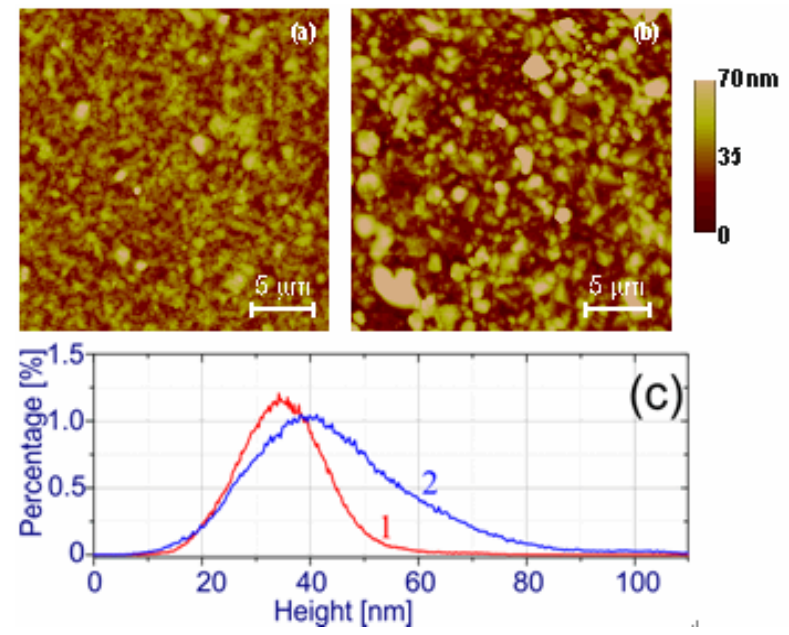

Figure1. AFM images of $\mathrm{ZnO}$ reference (a) and $\mathrm{Cu}$-doped (b) $\mathrm{ZnO}$ films deposited on $\mathrm{Si}$ substrate. Surface height histograms (c) for the corresponding films (curves 1,2).

The PL properties of $\mathrm{ZnO}$ films depend on the substrate temperature at film deposition and $\mathrm{Cu}$ doping level. For the $\mathrm{ZnO}$ films deposited at the low temperature of substrate $(T \mathrm{~s}=$ $150{ }^{\circ} \mathrm{C}$ ), the luminescence was not observed, which is related to the low crystal perfection of the films and a high concentration of nonradiative recombination centers in them [22]. Such films were selected specially in order the annealing-doping effect marked greatly. Emission becomes 
observable after doping and annealing of the films. The normalized PL spectra of the $\mathrm{ZnO}-\mathrm{Cu}$ films on Si substrate at low , mediate and high levels of doping are shown in Figures $2 \mathrm{a}$ and $2 \mathrm{~b}$ as well as the reference one (Figure 2a, curve 1). The PL spectrum of each film was normalized to the maximal value of the intensity in it. The spectra were normalized in order to present them in one figure because the PL intensities for the films are significantly different.
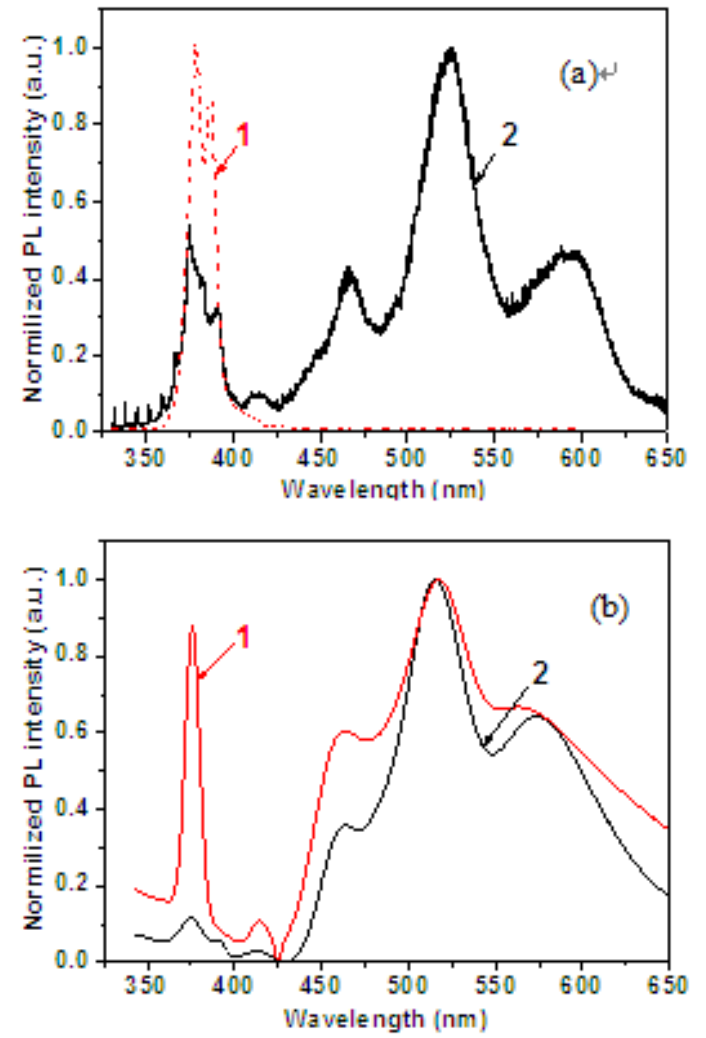

Figure 2. $\mathrm{Pl}$ spectra of $\mathrm{ZnO}$ films with different concentrations films of $\mathrm{Cu}$ : a) 1- the reference $\mathrm{ZnO}$ film, 2- the mediate concentration of $\mathrm{Cu}, \mathrm{b}$ ) 1 -the minimum and- 2 the maximum of $\mathrm{Cu}$ concentrations

After hydrothermal annealing at $600^{\circ} \mathrm{C}$, an intense UV emission of $\mathrm{ZnO}$ films is appeared. The luminescence spectrum of $\mathrm{ZnO}$ film has a narrow peak of UV luminescence at $375 \mathrm{~nm}$ with an approximate half-width of $15 \mathrm{~nm}$ and the absence of VS emission (Figure 2a, curve 1). The significant difference is observed between doped (Figure 2a, curve 2) and the reference films spectra (Figure $2 \mathrm{a}$, curve 1). After doping with $\mathrm{Cu}$, the suppression of UV component is observed and an intense visible spectra (VS) emission is appeared. It is correlated with other author's results $[15,23]$. The degree of suppression of the UV band is determined by the $\mathrm{Cu}$ concentration. The UV band is suppressed for 10 times at high $\mathrm{Cu}$ concentration (Figure2b, curve 2). The fine structure of the UV emission band is observed at mediate $\mathrm{Cu}$ concentration (Figure 2a, curve 2). The energy separation between adjacent peaks is about of 72 $\mathrm{meV}$. This value matches well with the longitudinal optical (LO) phonon energy in $\mathrm{ZnO}$. As a rule, phonon replicas have low intensity compared with the intensity of the UV bands. Thus, in the PL spectra, as a rule, only one to three longitudinal optical phonon features can be distinguished. We observed 6 phonon replicas. In fact, as a rule, such a structure is observed in the emission of single crystals at low temperature $\sim 77 \mathrm{~K}$ [24]. The presence of the phonon structure at ambient temperature suggests that the crystal structure of the films is of high quality. Phonon properties of our $\mathrm{ZnO}-\mathrm{Cu}$ films with mediate copper concentrations were investigated using the method of Raman scattering [25]. In the Raman spectra of the films authors observed from 6 to 8 phonon repetitions, similar to the bulk $\mathrm{ZnO}$ crystal. The presented results also clearly show that $\mathrm{ZnO}$ films obtained by the technique applied here possess rather perfect crystal structure which is really close to that of bulk $\mathrm{ZnO}$ single crystals [25].

The VS emission of $\mathrm{ZnO}$ films consists of the bands with the center at $415 \mathrm{~nm}, 465 \mathrm{~nm}, 520 \mathrm{~nm}, 580-600 \mathrm{~nm}$, respectively. The intensity of the small band at $415 \mathrm{~nm}$ does not depend on the $\mathrm{Cu}$ concentration and it intensity is very low (approximately of 5\%). The origin of the peak at 415 $\mathrm{nm}$ is attributed to the intrinsic defects [26, 27] and therefore, it is excluded out from the consideration in this paper. The VS emission intensity increases with increasing $\mathrm{Cu}$ concentration. The VS emission intensities are differ 5 times for low and high $\mathrm{Cu}$ concentration (Figure 2b, curves 1 and 2).Three peaks structure of the VS emission is expressed most clearly for the mediate concentration of copper (Figure 2a, curve 2).

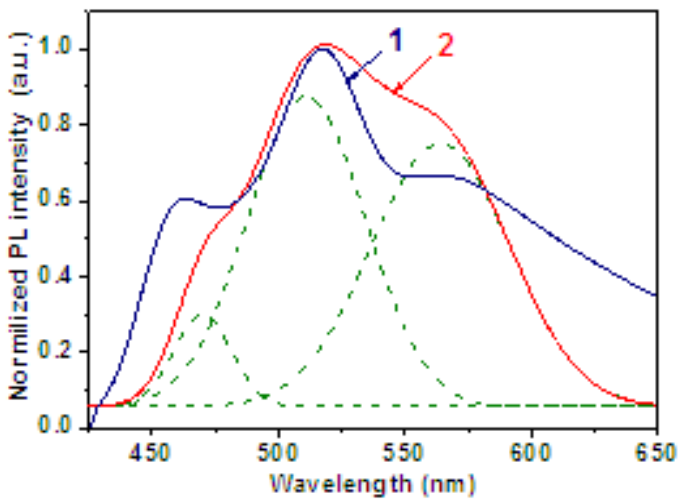

Figure3. PL spectra of $\mathrm{ZnO}-\mathrm{Cu}$ films on silicon (1) and sapphire (2) substrates at low level doping. The dashed lines show the results of the Gaussian multipeaks fitting

Figure 3 shows the VS emission spectra of the samples with low level doping but grown on different substrates $\mathrm{SiN}_{\mathrm{x}} / \mathrm{Si}$ (1) and $\mathrm{a}-\mathrm{Al}_{2} \mathrm{O}_{3}(2)$, respectively. At first sight the spectra are different greatly. The emission spectrum of $\mathrm{ZnO}-\mathrm{Cu}$ on $\mathrm{Al}_{2} \mathrm{O}_{3}$ substrate has a complex shape and we have resolved them into Gaussian component. We obtained the same three component - blue, green and orange - but with other intensities relationship. The difference between these spectra is due to the difference in the intensity ratios of the constituent bands. The first band is in a blue region with a maximum at $465 \mathrm{~nm}(2.67 \mathrm{eV})$. The second and third bands are in the green and orange regions with the maximum at 520 and $580-600 \mathrm{~nm}$, respectively. The green band is the most 
intensive. As a consequence, the emission looks like white light with $(0.31,0.43)$ color coordinate for the mediate concentration of copper. Only green band at $520 \mathrm{~nm}$ was observed in the spectrum of $\mathrm{ZnO}-\mathrm{Cu}$ film grown by EBE. The emission band has gauss shape in temperature range from $4.2 \mathrm{~K}$ to $300 \mathrm{~K}$.

In order to determine whether $\mathrm{Cu}$ ions penetrate into the depth of the film or they remain mainly on the surface, we investigated the cathodoluminescence (CL) spectra of the $\mathrm{ZnO}-\mathrm{Cu}$ films. It is known that a short wavelength light is absorbed at the surface of film while the electron beam excited of film's volume. The $\mathrm{CL}$ spectra of the $\mathrm{ZnO}$ (reference) and $\mathrm{ZnO}-\mathrm{Cu}$ films on sapphire substrate with the high concentration of $\mathrm{Cu}$ are shown on Figure 4 (curve 1 and 2, respectively). The $\mathrm{CL}$ spectrum of the $\mathrm{ZnO}$ film consists of the UV band and a very small VS emission. The UV band is suppressed greatly, VS emission is increased in the $\mathrm{ZnO}-\mathrm{Cu}$ film spectrum similar to their PL spectra. This is evidence of $\mathrm{Cu}$-doping of the film's volume.

The VS emission of CL demonstrate the three peak structure similar to the VS emission of PL, but the positions of the band peaks are different. The maxima of the emission bands observed upon excitation by an electron beam are shifted to the higher energies by $0.1 \mathrm{eV}$, comparing with the band maxima observed under optical excitation. This is due to the different conditions of emission centers formation within the film volume and at the film surface.

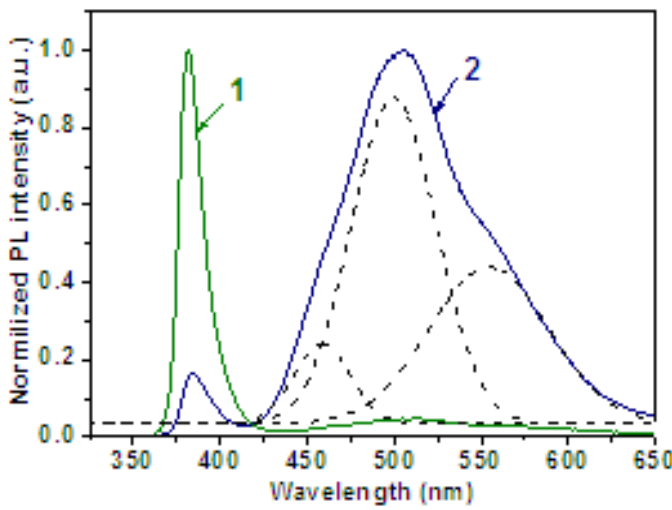

Figure 4. $\mathrm{CL}$ spectra of the $\mathrm{ZnO}$ reference (1) and $\mathrm{ZnO}$ - $\mathrm{Cu}$ with mediate concentration of $\mathrm{Cu}$ (2) films, respectively. The dashed lines show the results of the Gaussian multipeaks fitting.

S.U.Yuldashev, et al. [28] observed a similar three band structure of $\mathrm{ZnO}$ film white emission in $\mathrm{n}-\mathrm{Zn}_{0.9} \mathrm{Mg}_{0.1} \mathrm{O} / \mathrm{ZnO} / \mathrm{p}-\mathrm{Zn}_{0.9} \mathrm{Mg}_{0.1} \mathrm{O}$ heterojunction structures. It was found that the electroluminescence spectrum of this heterostructure consists of at least three emission bands. The first band is in a blue region with a maximum at 420 $\mathrm{nm}$. The second and third bands are in the green and orange regions with maximums at 505 and $610 \mathrm{~nm}$, respectively. The blue emission band is attributed to the radiative recombination of the donor-acceptor pairs (DAP), in which the acceptors are the nitrogen atoms, and this emission band might be originated from radiative recombination in the $\mathrm{p}$ $\mathrm{Zn}_{0.9} \mathrm{Mg}_{0.1} \mathrm{O}$. The green emission band is due to the recombination of DAP, where the deep donors are the vacancies of oxygen and the orange emission band is attributed to the oxygen interstitials. These last two emission bands originate from the $\mathrm{ZnO}$ active layer. However, following facts demonstrate the other structure of the centers of a luminescence $\mathrm{ZnO}-\mathrm{Cu}$ films. Similarity of $\mathrm{ZnO}-\mathrm{Cu}$ film's emission spectra on various substrates (see. Figure 3) shows that the luminescence centers might be attributed precisely to the $\mathrm{ZnO}$ film and not to its interface or to the substrate as in [29].

The dependence of the emission spectra on the doping level of copper (Figure 2) indicates that the luminescence centers are the copper ions or complexes, which include copper. It has been shown, that the copper doping gives three types of $\mathrm{Cu}_{\mathrm{Zn}}\left(3 \mathrm{~d}^{9}\right), \mathrm{Cu}_{\mathrm{Zn}}\left(3 \mathrm{~d}^{10}\right)$ and $\mathrm{Cu}_{\mathrm{i}}$ point defects in $\mathrm{ZnO}$ [15]. The first two are the acceptors in two charge states $-3 \mathrm{~d}^{9}$ and $3 \mathrm{~d}^{10}$ and the third is the donor. The $3 \mathrm{~d}^{9}$ state is in close proximity to the valence band. Another electronic state, $3 \mathrm{~d}^{10}$, lies deeper in the forbidden band of $\mathrm{ZnO}$. At high copper impurities concentrations it begins to compensate itself, forming the donor's and acceptor's point defects.

We can assume that the presence of three bands in the VS emission is caused by these defects. The reason for this is the following. The optical depths of the copper acceptor levels relative to the valence band are $0.1 \mathrm{eV}$ and $0.38 \mathrm{eV}$ for the two charge states $3 \mathrm{~d}^{9}$ and $3 \mathrm{~d}^{10}$, respectively [15]. The difference in the emission energy of $\mathrm{Cu}^{+}$and $\mathrm{Cu}^{++}$ luminescence centers should reach $0.28 \mathrm{eV}$. This value is in good agreement with the difference of the blue $(2.67 \mathrm{eV})$ and green $(2.38 \mathrm{eV})$ radiation energy of $0.29 \mathrm{eV}$.Orange band can be attributed to the impurity defects associated with interstitial copper in combination with its own lattice defect acceptors. The introduction of copper in $\mathrm{ZnO}$ in the form of three types of defects is a feature of copper doping by thermal diffusion techniques through the film surface. Doping from the target during film growth (EBE) provides luminescence centers of only one type. It follows from the results of hydrothermal annealing films with different copper concentrations obtained by EBE deposition. The emission spectra had only one green band at $520 \mathrm{~nm}$ in a wide temperature range from $4.2 \mathrm{~K}$ to $300 \mathrm{~K}$.

The UV radiation intensity attenuation with the copper introduction may be the result of the deterioration of the film's crystal structure or the appearance of competitive additional radiative recombination channels. However, the morphological and optical results indicate that the deterioration in crystal structure was not observed. AFM investigation of doped film's surface indicates a strongly developed surface with larger grains and nanocrystals in comparison with films without doping. The presence of the phonon replicas in the emission spectra indicates the high crystal quality of $\mathrm{ZnO}-\mathrm{Cu}$ films.

\section{Conclusions}

The close-space sublimation method was first applied for 
$\mathrm{Cu}$ doping of $\mathrm{ZnO}$ thin films. Doping was carried out throughout the whole thickness of the films. The crystal quality of $\mathrm{Cu}$ doped $\mathrm{ZnO}$ thin films has been improved, which follows from the AFM and optical studies. After doping with $\mathrm{Cu}$, an intense VS emission was appeared and the suppression of UV component was observed. The VS emission consists of the bands with the center at $465 \mathrm{~nm}, 520$ $\mathrm{nm}$ and $580-600 \mathrm{~nm}$. An intensity ratio of the constituent bands is determined by the $\mathrm{Cu}$ concentration and substrate type. The green band is the most intensive in the emission spectra. As a consequence, the emission looks like white light with $(0.31,0.43)$ color coordinate for the mediate concentration of copper. On the basis of the experimental data analysis it was found that the three types of point defects $\mathrm{Cu}_{\mathrm{Zn}}\left(3 \mathrm{~d}^{9}\right), \mathrm{Cu}_{\mathrm{Zn}}\left(3 \mathrm{~d}^{10}\right)$ and $\mathrm{Cu}_{\mathrm{i}}$ in $\mathrm{ZnO}$ are responsible for the VS emission. The introduction of copper into $\mathrm{ZnO}$ in the form of three type's defects is a feature of copper doping by thermal diffusion techniques through the film surface.

\section{Acknowledgements}

It's a pleasure to express our gratitude to Prof. G.V. Lashkarev for helpful discussions.

The work was partially financed within the program of National Academy of Sciences of Ukraine "Nanosystems, nanomaterials, nanotechnologies" (project No. 85/07-N).

The work was presented on the International research and practice conference "Nanotechnology and nanomaterials" (NANO-2014), 23-30, August 2014, Bukovel,Ukraine[16]

\section{REFERENCES}

[1] Ü. Özgür, Ya. I. Alivov, C. Liu, A. Teke, M. A. Reshchikov, S. Doğan, V. Avrutin, S. J. Cho, H. Morkoç. A comprehensive review of $\mathrm{ZnO}$ materials and devices, Journal of applied physics, Vol. 98, 041301, 1-103, 2005.

[2] A. Janotti, C. G. Van de Walle. Fundamentals of zinc oxide as a semiconductor, Reports on Progress in Physics, Vol.72, 126501, 1-29, 2009.

[3] J. J. Ding, Y. Ma, H. X. Chen, X. F. Shi, T. T. Zhou, L. M. Mao, Influence of Al-doping on the structure and optical properties of ZnO films, Physica B, Vol.404, 2439-2443.

[4] W. M. H. Oo, L. F. Saraf, M. H. Engelhard, V. Shutthanandan, L.Bergman, J. Huso, M. D. McCluskey. Suppression of conductivity in Mn-doped $\mathrm{ZnO}$ thin films, J. Appl. Phys., Vol.105, 013715, 1-4, 2009.

[5] A. Tubtimtae, M. W. Lee. $\mathrm{ZnO}$ nanorods on undoped and indium-doped $\mathrm{ZnO}$ thin films as a TCO layer on nonconductive glass for dye-sensitized solar cells, Superlattice. Microst., Vol.52, 987-990,2012.

[6] K. Kobayashi, H. Udaka, N. S. Matsushima, G. Okada. Photoinduced charge transfer of $\mathrm{Cu}$-doped $\mathrm{ZnO}$ film, Journal of Material Science Letters, Vol.13, 103-107, 1994.
[7] T. G. Kryshtab, V. S. Khomchenko, V. P. Papusha, M. O. Mazin, Yu. A. Tzyrkunov. Thin $\mathrm{ZnS}: \mathrm{Cu}$, $\mathrm{Ga}$ and $\mathrm{ZnO}: \mathrm{Cu}$, Ga film phosphors, Thin Solid Films, Vol.403-404, 76-80,2002.

[8] A. N. Gruzintsev, V. T. Volkov, E. E. Yakimov. Photoelectrical properties of $\mathrm{ZnO}$ films, doped with acceptor impurities $\mathrm{Cu}$ and $\mathrm{Ag}$, Semiconductors, Vol.37, No.3, 259-262.

[9] D. R. Lide. CRC Handbook of Chemistry and Physics, CRC Press Inc., London, 1994.

[10] T. G. Kryshtab, V. S. Khomchenko, V. B. Khachatryan, N.A.Roshina, J. A. Andracha-Adame, O. S. Lytvyn, V. I. Kushnirenko. Effect of doping on properties of $\mathrm{ZnO}: \mathrm{Cu}$ and $\mathrm{ZnO}: \mathrm{Ag}$ thin films. Journal of Material Science: Material Electronics, Vol.18, 1115-1118, 2007.

[11] H. Liu, J. Yang, Z. Hua, Y. Zhang, I. Yang, I. Xiao, Z. Xie. The structure and magnetic properties of $\mathrm{Cu}$-doped $\mathrm{ZnO}$ prepared by sol-gel method, Appl. Surf. Sci, Vol.256,4162-4167,2010.

[12] V. Cracium, J. Elders, J. Gardeniers, I. W. Boyd. Characteristics of high quality $\mathrm{ZnO}$ thin films deposited by pulsed laser deposition, Journal Applied Physics Letters, Vol.65, 2963-2969.

[13] A. Evtushenko, V. Karpyna, G. Lashkarev, V. Lazorenko, V. Baturin, A. Karpenko, M. Lunika, A. Dan'ko. Multilayered ZnO Films of Improved Quality Deposited by Magnetron Sputtering, J. Acta Physica Polonica A, Vol.114, №5, 1131-1137, 2008.

[14] V. S. Khomchenko,T. G. Kryshtab, A. K. Savin, L. V. Zayalova, N. N. Roshina, V. E. Rodionov, O. S. Lytvyn, V. I. Kushnirenko, V. B. Khachatryan, J. A. Andracha-Adame. Fabrication and properties of $\mathrm{ZnO}: \mathrm{Cu}$ and $\mathrm{ZnO}: \mathrm{Ag}$ thin films, Superlattices and Microstructures, Vol.42, 94-98, 2007.

[15] A. N. Gruzintsev, V. T. Volkov, I. I. Khodos, T. V. Nikiphorova, M. N. Kovalchuk. Luminescent properties of $\mathrm{ZnO}$ films, doped with acceptor impurities: $\mathrm{Cu}, \mathrm{Ag}, \mathrm{Au}$, Russian microelectronics, Vol.31, No.3, 200-205, 2002.

[16] V. S. Khomchenko, S. U. Yuldashev, S. I. Vlaskina, V. E. Rodionov. White light emission of $\mathrm{ZnO}-\mathrm{Cu}$ film, International research and practice conference "Nanotechnology and nanomaterials" (NANO-2014). August 23-30,189, 2014, Bukovel.

[17] V. S. Khomchenko, V. E. Rodionov, Yu. A. Tzyrkunov L. I. Berezhinsky. New method of thin films doping, Proceedings of the 7th International Symposium "Advanced Display Technologies", Minsk, Belarusia, 218-220, 1998.

[18] T. G. Kryshtab, V. S. Khomchenko, J. A. Andraca-Adame, A. K. Savin, A. V. Kryvko, G. Juarez, R. Pena-Sierra. Luminescence and structure of $\mathrm{ZnO}-\mathrm{ZnS}$ thin films prepared by oxidation of $\mathrm{ZnS}$ films in air and water vapor, Journal of Luminescence, Vol.129, 1677-1681, 2009.

[19] X. Chen, A. M. Ch, Ng, A. B. Djurisic, C, Ch. Ling, W. K.Chan. Hydrothermal treatment of $\mathrm{ZnO}$ nanostructures, Thin Solid Films, Vol.520, 2656-2662, 2012.

[20] O. Lupan, T. Pauporte, I. M. Tiginyanu, V. V. Ursaki, V. Sontea, L. K. Ono, B. Roldan Cuenya, L. Chow. Comparative study of hydrothermal treatment and thermal 
annealing effects on properties of electrodeposited micro-columnar $\mathrm{ZnO}$ thin films, Thin Solid Films, Vol.519, 7738-7749, 2011.

[21] Z. Yu. Gontra. The handbook on technology of microelectronic device, Kamenyr, Lviv, 1986.

[22] G. V. Lashkarev, V. I. Lazorenko, A. I. Evtushenko, V. D. Khranovskyy, L. V. Blonskyy, I. M. Dmitruk, T. Sh. Osmanov. Effect of the deposition technology and structure of $\mathrm{ZnO}$ films on their photo-and cathodoluminescence, Ukrainian Journal of Physics, Vol.53, No.9, 867-872, 2008.

[23] Ja. I. Alivov, M. V. Chukichev, V. A. Nikitenko. Green band of luminescence in zinc oxide films doped in the process of thermal diffusion, Physic and technique of semiconductors, Vol. 38, issue 1, 34-38, 2004.

[24] C. Klingshirn. ZnO:From basics towards applications, Phys. Stat. Solidi B,Vol. 244, 3027-3073, 2007.
[25] G. Lashkarev, V. Karpyna, A. Yaremko. Multi-phonon excitations textured crystalline films by Raman spectroscopy, Thin Solid Films, Vol.520, 6499-6502, 2012.

[26] Xingping Peng, Jinzhang Xu, Hang Zang, Boyu Wang, Zhiguang Wang. Structural and PL properties of Cu-doped $\mathrm{ZnO}$ films, Journal of Luminescence, Vol. 128, 297-300, 2008 .

[27] Gong-Ru Lin,S. C. Wang. Comparison of High-Resistivity ZnO Films Sputtered on Different Substrates, Japan. J. Appl. Phys. Vol. 41, L 398-L 401, 2002.

[28] S. U. Yuldashev, R. A. Nusretov, I. V. Khvan, V. Sh. Yalishev, T. W. Kang. White light emission from $\mathrm{ZnO} / \mathrm{Zn} 0.9 \mathrm{Mg} 0.1 \mathrm{O}$ heterostructures grown on Si substrates, Japanese Journal of Applied Physics, Vol.47, No.1, 133-135, 2008.

[29] E. Kayahan. White light luminescence from annealed thin $\mathrm{ZnO}$ deposited porous silicon, Journal of Luminescence, V.130, 7, 1295-1299, 2010. 